\title{
Local cross-border disease surveillance and control: experiences from the Mekong Basin
}

Melinda Moore ${ }^{1 *}$ and David J Dausey ${ }^{1,2}$

\begin{abstract}
Background: The Mekong Basin Disease Surveillance cooperation (MBDS) is one of several sub-regional disease surveillance networks that have emerged in recent years as an approach to transnational cooperation for infectious disease prevention and control. Since 2003 MBDS has pioneered a unique model for local cross-border cooperation. This study examines stakeholders' perspectives of these MBDS experiences, based on a survey of local managers and semi-structured interviews with MBDS leaders and the central coordinator.

Results: Fifteen managers from 12 of 20 paired cross-border sites completed a written survey. They all monitor most or all of the 17 diseases agreed upon for MBDS surveillance information sharing. Fourteen agreed or strongly agreed with statements about the core MBDS values of cooperation, mutual trust, and transparency, and their own contributions to national and regional disease control (average score of 4.4 of 5.0). Respondents felt they implemented well to very well activities related to surveillance reporting (average scores 3.4 to 3.9 of 4.0), using computers for their work (3.9/4.0), and using surveillance data for action (3.8/4.0). Respondents reported that they did worst in implementing research (2.1/4.0) and somewhat poorly for local laboratory testing (2.9/4.0) and local coordination with cross-border counterparts (2.9/4.0), although all 15 maintain a list with contact information for these counterparts and many know their counterparts. Implementation of specified activities within their collective regional action plan was uneven across the cross-border sites. Most respondents reported positive lessons learned about local cooperation, information sharing and joint problem solving, based on trusting relationships with their cross-border counterparts. They recommend expansion of cross-border sites within MBDS and consideration of the cross-border cooperation model by other sub-regional networks.
\end{abstract}

Conclusions: MBDS has over a decade of experience with its model of local cross-border cooperation in disease surveillance and control. Frontline managers have documented success with this model, strongly support it and recommend its expansion within and beyond the MBDS network. The MBDS cross-border cooperation model is standing the test of time as a solid approach to building and sustaining the public health capabilities needed for disease surveillance and control from the local to national and global levels.

Keywords: Surveillance, Regional, Sub-regional, Network, Cross-border, Cooperation, Mekong, International Health Regulations, Public health, Global health

\section{Background}

In today's globalized world, infectious disease threats have become transnational in nature and therefore require effective transnational approaches for detection, response and prevention [1-5]. Through the World Health Organization's (WHO) International Health Regulations (IHR), nearly all countries around the world have committed to develop and maintain core public health capacities needed

\footnotetext{
* Correspondence: mmoore@rand.org

${ }^{1}$ Health Unit, RAND Corporation, Arlington, VA, USA

Full list of author information is available at the end of the article
}

to detect, diagnose, report and respond to public health threat [6]. Countries that can do so have committed to help other countries develop their core capacities. However, the foundation of transnational detection and response begins locally, where diseases occur. Local officials are on the front lines of public health surveillance and response (Figure 1).

Self-organized sub-regional disease surveillance networks have emerged in recent years as a model of transnational public health cooperation for disease surveillance and control [5,7-17]. Such networks have a bottom-up 


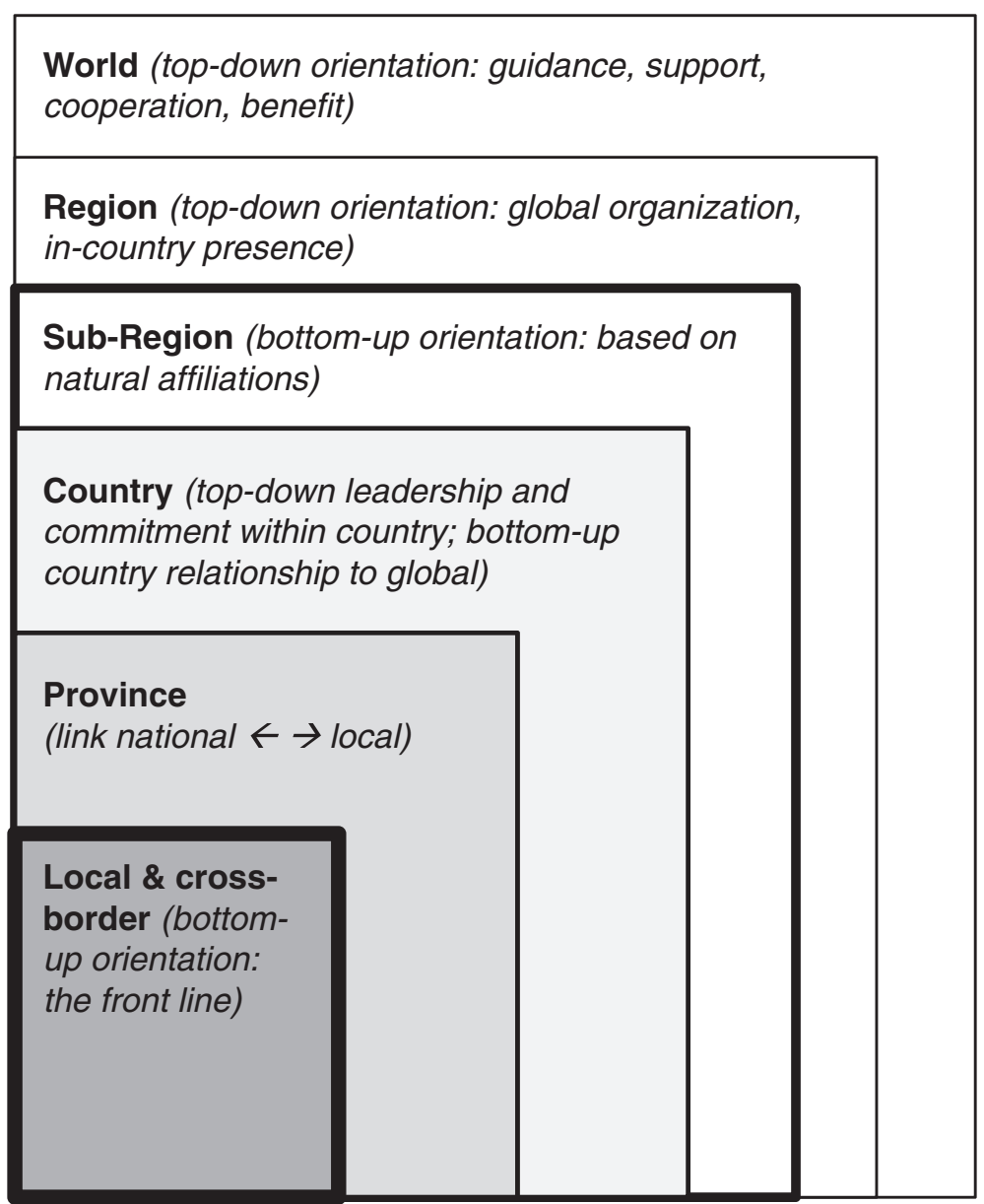

Figure 1 Local officials are at the front lines of public health.

orientation in the sense that they are self-organized affiliations rather than assigned ones. They contrast with regions organized in a top-down fashion, such as those designated by WHO.

The Mekong Basin Disease Surveillance (MBDS) cooperation is one of the longest standing sub-regional disease surveillance networks [7,9]. MBDS includes Cambodia, Lao PDR, Myanmar, Thailand, Vietnam and the Yunnan and Guangxi provinces of China. Organized initially in 1999 and formalizing its cooperation in 2001, MBDS has country level managers and a coordinator's office located in Bangkok, Thailand. MBDS stakeholders organized their activities based on multi-year action plans generated by MBDS members and leadership. The plan in place at the time of this study was for 20112016 and specified seven strategic areas for national action and sub-regional cooperation: cross-border (XB) cooperation; strengthening the animal-human health interface and community surveillance; epidemiology capacity building; laboratory capacity building, information and communications capacity building; risk communications; and policy research [18]. Through its $\mathrm{XB}$ strategy, MBDS has pioneered a specific type of model for cooperation: a multi-country networked system of local XB sites to cooperate directly on disease surveillance, information sharing and joint investigation across local international borders [9].

The term "cross-border" in the context of public health and disease is commonly used as a synonym for "transnational" [19-22] rather than referring literally to local collaborations across international borders. Examples of the former focus on descriptions of cross-border disease threats [7,19-21]. Examples of the latter focus on local cross-border surveillance cooperation [7-9,23], "cross-border sharing of human resources and expertise [7], "[stamping] out the cross-border [dengue] outbreak" [7], "cross-border response teams [7], cross-border communications [8], and meetings at cross-border sites $[8,9,23]$. Some uses of the term are more ambiguous as to whether such actions as cross-border population movements [7,14,23], cross-border trade [7], cross-border collaboration [7], and cross-border communications $[7,8]$ 
refer to broad or more local transnational concepts, or both.

Between 2003 and 2012, MBDS established 25 XB demonstration sites. These provide a unique, "bottomup," complementary approach to local, national and transnational disease surveillance and control. This report focuses on the MBDS experience with local XB cooperation in disease surveillance and control. It describes insights about such cooperation as seen from various perspectives. These include the perspectives of local XB site managers, who are responsible for implementing and managing activities at their site; MBDS country leaders, who are responsible for coordinating MBDS efforts in their country and contributing to decision making through the MBDS Executive Board; and the MBDS central coordinator, who is responsible for coordinating efforts across all MBDS countries. The study reported here examines the following research questions:

1. How well do local XB health authorities understand their role in national surveillance, MBDS networking, and the WHO International Health Regulations?

2. Which areas specified for MBDS cooperation are current public health priorities at the local level?

3. How well have MBDS strategic priorities and activities been implemented at XB sites?

4. To what extent is surveillance data/information shared and used locally?

5. What aspects of surveillance are working well and less well at these sites?

6. What was the sequence of activities in developing the XB sites?

7. What activities are viewed as the most important or valuable at $\mathrm{XB}$ sites?

8. What lessons have been learned from XB cooperation, and what advice could be offered to others?

9. What are the prospects for sustainability of $\mathrm{XB}$ cooperation, including enabling factors and barriers?

Insights from this study not only help to improve MBDS's own programming but also are valuable to inform cooperation in other disease surveillance networks that span international borders or require communication and coordination across different agencies and organizations. In addition, public health workers broadly focused on disease surveillance may find the results of the study helpful as they consider collaborative approaches to disease surveillance.

\section{Methods}

The study was carried out from January 2012 to January 2013. During this time period, 20 of the 25 designated
MBDS XB demonstration sites had one or both sides operational. After consultation with leaders in the MBDS member countries, the coordinator requested in writing that RAND's human subjects protection committee carry out the ethical review on their behalf. Therefore, RAND's human subjects protection committee approved the study on behalf of both RAND and MBDS. Data collection included a written survey during 2012 and semistructured interviews in early 2013, both of which included verbal informed consent that had been approved by RAND's ethical review committee.

The survey questionnaire was presented and completed in English by local XB site managers. It included both open-ended questions and closed-ended questions with checked, binary (yes or no), or scaled (1 to 4 or 1 to 5) responses (see Additional file 1). The targeted survey sample included all MBDS XB sites, including those pairs operating on both sides of the border and pairs where only one side of the border was operational. The MBDS central coordinator worked with MBDS country leaders to ensure that representatives from as many sites as possible had an opportunity to complete the survey. Survey information was collected via written questionnaire and transmitted electronically to the study team. A total of $15 \mathrm{XB}$ local site managers in five of the six MBDS countries completed surveys. These managers represented 12 of the 20 different $\mathrm{XB}$ sites active at the time of the survey (Table 1). These included paired forms from both sides of four XB sites (one site in Lao PDR is part of two different pairs) and single forms from eight additional sites. Responses to the survey's closedended questions were tallied and averaged. Responses to the open-ended questions were extracted, arrayed, and either listed or summarized.

In addition, the RAND study team completed face-toface interviews with two MBDS country leaders and the MBDS central coordinator in early 2013. These discussions explored how and why certain program elements were more or less successful than others, to help inform replication or new approaches in the future. As with the open-ended survey questions, responses were extracted, arrayed and either listed or summarized.

\section{Results and discussion}

All respondents indicated that they monitor at least 14 of the 17 diseases or conditions agreed upon for MBDS surveillance information sharing (acute flaccid paralysis, avian influenza, Chikungunya fever, cholera, dengue, diphtheria, encephalitis, human immunodeficiency virus [HIV], leptospirosis, malaria, measles, meningitis, pneumonia, severe acute respiratory syndrome [SARS], tetanus, tuberculosis, and typhoid); ten indicated that they monitor all 17 of these. Overall and not surprisingly, survey respondents from the 15 sites were most 
Table 1 MBDS cross-border sites and source of completed survey forms

\begin{tabular}{|c|c|c|c|c|c|c|c|c|c|}
\hline \# & Status & Year started & \# forms received & Cambodia & China & Laos & Myanmar & Thailand & Vietnam \\
\hline 1 & $\bullet$ & 2003 & 1 & & & Savannakhet (a) & & Mukdahan & \\
\hline 2 & $\bullet$ & 2003 & 0 & & & Savannakhet (b) & & & Quang Tri \\
\hline 3 & $\bullet$ & 2003 & 2 & Stung Treng & & Champasak (a) & & & \\
\hline 4 & $\bullet$ & 2003 & 0 & & Mengla (Yunnan) & Luang Namtha & & & \\
\hline 5 & $\bullet$ & 2008 & 0 & & & Bo Kaeo & & Chiang Rai (a) & \\
\hline 6 & $\bullet$ & 2008 & 2 & Banteay Mean Chey & & & & Sakaeo & \\
\hline 7 & $\bullet$ & 2008 & 1 & Takaeo & & & & & An Giang \\
\hline 8 & $\bullet$ & 2008 & 1 & Kampot & & & & & Kien Giang \\
\hline 9 & $\bullet$ & 2008 & 1 & & Luchun (Yunnan) & & & & Lai Chau \\
\hline 10 & $\bullet$ & 2008 & 1 & & Ping Xiang (Guangxi) & & & & Lang Son \\
\hline 11 & $\bullet$ & 2009 & 1 & & & Borikhamxay & & & Ha Tinh \\
\hline 12 & $\bullet$ & 2009 & 0 & & & Vientiane & & Nongkhai & \\
\hline 13 & $\bullet$ & 2009 & 0 & & & Sayabury & & Nan & \\
\hline 14 & $\bullet$ & 2011 & 2 & Koh Kong & & & & Trat & \\
\hline 15 & $\theta$ & 2011 & 0 & & Dong Xing (proposed) & & & & Guang Ninh \\
\hline 16 & $\ominus$ & 2011 & 0 & Kampong Cham & & & & & Tay Ninh (a) \\
\hline 17 & $\theta$ & (2012) & 2 & & & Champasak (b) & & Ubon Ratchathani & \\
\hline 18 & $\theta$ & (2012) & 1 & Svay Rieng & & & & & Tay Ninh (b) \\
\hline 19 & $\theta$ & (2012) & 1 & & & & Myawaddy & Mae Sot & \\
\hline 20 & $\theta$ & (2012) & 0 & & Dong Xing & & & & Mong Cai \\
\hline 21 & $\mathrm{O}$ & (2012) & 0 & & & & Tachilake & Chiang Rai (b) & \\
\hline 22 & O & (2012) & 0 & Battambang \& Pailin & & & & Chanthaburi & \\
\hline 23 & $\mathrm{O}$ & (2012) & 0 & & & Khammouane & & Nakorn Phanom & \\
\hline 24 & $\mathrm{O}$ & (2012) & 0 & & & Khammouane & & & Quang Binh \\
\hline 25 & $\mathrm{O}$ & (2012) & 0 & & & & Kawthaung & Ranong & \\
\hline
\end{tabular}

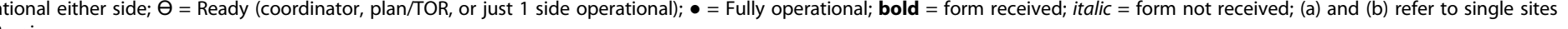
that are part of more than one XB pair. 
familiar with their own country's surveillance system and their local MBDS XB cooperation (Table 2). They reported being well aware of the WHO IHR in general but they were less aware of specific elements of the IHR. They were more aware of the MBDS central coordinator and his office, which communicates relatively regularly with the XB sites, than with the MBDS country leaders. Respondents whose counterparts across the border did not complete the survey (reflected as "Singles" in Table 2) were more aware of nearly all aspects of MBDS, their country's surveillance, and the IHR, compared to respondents whose $\mathrm{XB}$ counterparts did complete the survey (reflected as "Pairs" in Table 2). Familiarity with MBDS, national surveillance and the IHR was somewhat lower for respondents from the four sites in Thailand (average score of 2.8 of 5.0) compared to those from the six sites in Cambodia (4.1/5.0) or the three sites in Vietnam (4.0/5.0). No information on the surveys or in the interviews pointed to the reasons for these differences.

Respondents were asked which of 11 specific surveillancerelated activities or capacities are priorities for their country, MBDS, and/or the WHO IHR:

- Infectious disease surveillance

- Timely surveillance reporting

- Using surveillance information for action

- Public health capacity building

- Laboratory capacity

- Epidemiology capacity building

- Risk communications

- Communications technology capacity

- Surveillance at points of entry

- Public health emergencies of international concern

\section{- Coordination of animal and human health}

The vast majority of respondents $(13 ; 87 \%)$ indicated that all 11 of these are important to their country (overall average 10.8/11); 10 (67\%) indicated that all 11 are important for MBDS (9.9/11.0); and 6 (40\%) indicated that all 11 are important to the IHR (8.9/11). These findings are consistent with respondents' higher familiarity with their own national surveillance system and MBDS cooperation than with details of the WHO IHR, though general familiarity with the WHO IHR is relatively high (average score for awareness/familiarity of 4.0 of 5.0).

Nearly all respondents (14; 93\%) agreed or strongly agreed with all statements about the importance of MBDS cooperation, trust, and transparency; the consistency of MBDS with the country's own surveillance and response system; the contribution of their own work to the country's surveillance system; and the importance of exercises and drills (Table 3). A small minority of respondents $(3 ; 20 \%)$ was neutral about the statement that their work serves the MBDS system. One respondent in Thailand appeared to be an outlier and disagreed or strongly disagreed with all of these statements.

Most respondents consider that they implement moderately to very well most of the general activities associated with MBDS (Table 4). These include reporting surveillance data to their country surveillance system (average score 3.9 of 4.0), their XB partner (3.4/4.0) and the MBDS Coordinator (3.5/4.0); using their surveillance data for local action (3.8/4.0); responding locally to disease outbreaks (3.7/4.0); coordinating human and animal health (3.2/4.0); conducting community-based surveillance (3.4/4.0); using computers in their work (3.9/4.0); and

Table 2 Respondent awareness/familiarity with MBDS

\begin{tabular}{|c|c|c|c|c|c|c|}
\hline \multirow[t]{3}{*}{ Description (Item) } & \multicolumn{6}{|c|}{ Average score } \\
\hline & \multicolumn{6}{|c|}{ (Scale: 1 not aware to 5 very aware) } \\
\hline & ALL & Pairs & Singles & Cambodia & Thailand & Vietnam \\
\hline Number of sites & 15 & 7 & 8 & 6 & 4 & 3 \\
\hline MBDS - general & 3.4 & 2.9 & 3.9 & 3.2 & 2.8 & 4.0 \\
\hline MBDS - Executive board & 3.5 & 2.4 & 4.5 & 3.7 & 2.5 & 4.3 \\
\hline MBDS - Country coordinator & 3.9 & 3.3 & 4.4 & 4.2 & 2.8 & 4.3 \\
\hline MBDS Coordinator/coordinating office & 4.0 & 3.4 & 4.5 & 4.7 & 2.8 & 4.3 \\
\hline MBDS Action plan and strategies & 3.8 & 3.4 & 4.1 & 3.7 & 3.0 & 4.3 \\
\hline Cross-border (XB) cooperation & 4.1 & 3.9 & 4.4 & 4.7 & 3.5 & 4.0 \\
\hline Your country's surveillance program & 4.3 & 4.3 & 4.4 & 4.5 & 3.5 & 4.7 \\
\hline IHR & 4.0 & 4.1 & 3.9 & 4.5 & 3.3 & 3.3 \\
\hline IHR reporting requirements & 3.5 & 3.0 & 3.9 & 4.0 & 2.3 & 3.7 \\
\hline IHR core capacities & 3.3 & 2.9 & 3.8 & 4.0 & 2.0 & 3.3 \\
\hline Total & 3.8 & 3.4 & 4.2 & 4.1 & 2.8 & 4.0 \\
\hline
\end{tabular}


Table 3 Values and context as reported by respondents

\begin{tabular}{|c|c|c|c|c|c|c|}
\hline \multirow[t]{3}{*}{ Description (Item) } & \multicolumn{6}{|c|}{ Average score } \\
\hline & \multicolumn{6}{|c|}{ (Scale: 1 strongly disagree to 5 strongly agree) } \\
\hline & ALL & Pairs & Singles & Cambodia & Thailand & Vietnam \\
\hline Number of sites & 15 & 7 & 8 & 6 & 4 & 3 \\
\hline MBDS cooperation is important & 4.4 & 4.3 & 4.6 & 4.8 & 3.5 & 4.5 \\
\hline MBDS is a pioneer for cooperation & 4.5 & 4.7 & 4.3 & 4.5 & 3.5 & 4.3 \\
\hline Mutual trust is important in MBDS & 4.5 & 4.1 & 4.8 & 4.5 & 3.8 & 5.0 \\
\hline Transparency is important in MBDS & 4.5 & 4.1 & 4.9 & 4.8 & 3.5 & 5.0 \\
\hline Your work serves MBDS system & 4.1 & 3.7 & 4.5 & 4.3 & 3.8 & 4.3 \\
\hline Your work serves country system & 4.4 & 4.1 & 4.6 & 4.5 & 3.8 & 4.7 \\
\hline MBDS is consistent with country's surveillance and response system & 4.3 & 3.9 & 4.6 & 4.3 & 4.0 & 4.7 \\
\hline Exercises (tabletops, simulations) and drills are important & 4.5 & 4.1 & 4.9 & 4.7 & 4.0 & 4.7 \\
\hline Total & 4.4 & 4.1 & 4.6 & 4.6 & 3.7 & 4.7 \\
\hline
\end{tabular}

carrying out risk communications (3.4/4.0). Respondents felt that they conducted joint outbreak investigations (2.9/ 4.0) and local laboratory testing (2.9/4.0) somewhat more poorly, and conducted applied or other research poorly or not at all (2.1/4.0). (A possible explanation for the low perceived quality of policy research implementation is that $\mathrm{XB}$ sites would not necessarily initiate, carry out or even be aware of such research.) Respondents at sites from which both XB partners completed the survey ("Pairs") reported better coordination (3.1/4.0) and surveillance reporting (3.7/4.0) to their $\mathrm{XB}$ partner compared to respondents whose $\mathrm{XB}$ counterpart did not complete the survey ("Singles", $2.8 / 4.0$ and 3.1/4.0, respectively).
Respondents from the six sites in Cambodia felt that their lab testing (2.5/4.0), joint outbreak investigations (2.3/4.0), and coordination of human and animal health (2.8/4.0) were more poorly implemented than respondents from Thailand (3.3/4.0, 3.0/4.0, 3.5/4.0, respectively) or Vietnam (3.3/4.0, 4.0/4.0, 3.3/4.0, respectively). Nearly all respondents look at and report their surveillance data, but somewhat fewer analyze or use these data on a regular basis (Table 5).

The XB managers were asked to indicate whether they implement a number of specific activities that are relevant to $\mathrm{XB}$ sites, i.e., linked to the first six key strategies in the MBDS Action Plan for 2011-2016. (In contrast,

Table 4 Respondent perception of quality of local implementation

\begin{tabular}{|c|c|c|c|c|c|c|}
\hline \multirow[t]{3}{*}{ Description (Item) } & \multicolumn{6}{|c|}{ Average score } \\
\hline & \multicolumn{6}{|c|}{ (Scale: 1 do not implement to 4 implement very well) } \\
\hline & $\overline{A L L}$ & Pairs & Singles & Cambodia & Thailand & Vietnam \\
\hline Number of sites & 15 & 7 & 8 & 6 & 4 & 3 \\
\hline Coordinate, talk, and/or meet with XB counterparts & 2.9 & 3.1 & 2.8 & 2.7 & 3.5 & 2.7 \\
\hline Report surveillance data to country system & 3.9 & 4.0 & 3.9 & 4.0 & 3.8 & 4.0 \\
\hline Report surveillance data to XB partner & 3.4 & 3.7 & 3.1 & 3.8 & 3.5 & 2.7 \\
\hline Report surveillance data to MBDS Coordinator & 3.5 & 3.7 & 3.4 & 3.8 & 3.5 & 3.3 \\
\hline Use your surveillance info for action & 3.8 & 3.9 & 3.8 & 4.0 & 3.8 & 3.7 \\
\hline Local outbreak response/investigation & 3.7 & 3.9 & 3.6 & 3.8 & 3.5 & 3.7 \\
\hline Joint XB outbreak response/investigation & 2.9 & 2.4 & 3.3 & 2.3 & 3.0 & 4.0 \\
\hline Coordinate human-animal health & 3.2 & 3.1 & 3.3 & 2.8 & 3.5 & 3.3 \\
\hline Conduct community-based surveillance & 3.4 & 3.1 & 3.6 & 3.2 & 3.5 & 3.7 \\
\hline Build and use epidemiology capacity & 3.3 & 3.1 & 3.5 & 3.0 & 3.5 & 3.7 \\
\hline Conduct lab testing for priority diseases & 2.9 & 2.7 & 3.1 & 2.5 & 3.3 & 3.3 \\
\hline Use computers for your routine work & 3.9 & 3.7 & 4.0 & 4.0 & 3.8 & 4.0 \\
\hline Conduct risk communications & 3.4 & 3.1 & 3.6 & 3.3 & 3.3 & 3.7 \\
\hline Conduct applied or other research & 2.1 & 1.4 & 2.8 & 2.0 & 2.0 & 2.7 \\
\hline Total & 3.3 & 3.2 & 3.4 & 3.2 & 3.4 & 3.5 \\
\hline
\end{tabular}


Table 5 Use of surveillance data by respondents

\begin{tabular}{|c|c|c|c|c|c|c|}
\hline \multirow[t]{2}{*}{ Description (Item) } & \multicolumn{6}{|c|}{ Percentage of sites reporting "Yes" } \\
\hline & ALL & Pairs & Singles & Cambodia & Thailand & Vietnam \\
\hline Number of sites & 15 & 7 & 8 & 6 & 4 & 3 \\
\hline Look at data & $93 \%$ & $100 \%$ & $88 \%$ & $100 \%$ & $100 \%$ & $67 \%$ \\
\hline Analyze data & $87 \%$ & $86 \%$ & $88 \%$ & $83 \%$ & $75 \%$ & $100 \%$ \\
\hline Use data & $87 \%$ & $86 \%$ & $88 \%$ & $83 \%$ & $100 \%$ & $67 \%$ \\
\hline Report data & $93 \%$ & $100 \%$ & $88 \%$ & $100 \%$ & $75 \%$ & $100 \%$ \\
\hline Average (of 4 possible actions) & 3.6 & 3.7 & 3.5 & 3.7 & 3.5 & 3.3 \\
\hline
\end{tabular}

the seventh strategy, policy research, does not specifically involve activities at all XB sites.) All respondents reported that they maintain a list of contact information for their XB counterparts (Table 6). Nearly all have a basic package of activities for their site and share surveillance information as required (for agreed-upon diseases at specified frequencies). More than three-fourths have ever participated in a joint XB outbreak investigation; slightly more than half have participated in at least one meeting with their XB counterpart or had a supervisory visit during the preceding six months. Of the six MBDS strategies reflected in the table, implementation of specific activities associated with epidemiology capacity (present all sites) and XB cooperation (average 5.3 of 7 different XB-specific activities implemented) was most common. Activities associated with information and communications technology capacity (average 3.6 of 4 different activities in this area), animal-human health interface and community surveillance (average 4.5 of 7 different activities), risk communications (average 1.1 of 2 activities), or laboratory capacity (average 1.6 of 3 different activities) were less common. The fifteen sites implement an average 17.0 of the total 24 activities. The six Cambodian sites reported implementing more activities (average 18.7/24) than the four sites in Thailand (average $16.0 / 24$ ) or the two sites reporting from Vietnam (average $15.0 / 24)$.

Respondents commented on the first activities needed to start up an $\mathrm{XB}$ site, which $\mathrm{XB}$ activities have been most valuable, and lessons they have learned about $\mathrm{XB}$ cooperation. Nearly all reported that initial activities included meetings with national or provincial authorities as well as their XB counterparts, orientation and training, and sharing surveillance information with $\mathrm{XB}$ partners. Nearly all also reported that the most valuable activities were sharing information, meeting regularly, and conducting joint outbreak investigations with $\mathrm{XB}$ counterparts. Most reported positive lessons learned about local cooperation, information sharing and joint problem solving, all based on trust, mutual respect and good relationships with $\mathrm{XB}$ counterparts. Respondents also offered advice to future MBDS XB sites or to other countries or networks that may establish similar sites. They recognized the importance of initial local and cross-border orientation, regular meetings with $\mathrm{XB}$ counterparts to maintain good relationships, an established agreement at the XB site, and openness and timeliness in sharing surveillance information across borders. Based on their experiences, they recommend expansion of the XB model more broadly across MBDS and feel that it is a worthwhile model for other sub-regional networks to consider.

Nearly all respondents commented on the aspects of surveillance that are working well at their site. Responses varied, with no consensus themes. Some of the reported well-functioning elements included both routine casebased and community event-based reporting, coordination from national to local level, and the availability of specific guidelines and communications technologies for surveillance reporting. Several respondents also commented on aspects of surveillance that are not working well. These include village level community surveillance (functioning well at some sites but not well at others), lack of local laboratory testing availability, and limited budget and staff motivation or participation. Most respondents explicitly noted the importance of the sustainability of their XB cooperation. They were at least moderately confident that they could sustain their efforts if they could maintain their good relationships with $\mathrm{XB}$ counterparts and receive sufficient technical and especially financial support.

Interviews with the two senior country level MBDS managers and the MBDS central coordinator reinforced and expanded upon the insights provided by the XB survey respondents. They all recognized the strengths and weaknesses of MBDS cooperation over time. Strengths include acknowledgement of the XB model as a good foundation for building trust, sharing surveillance information, conducting joint outbreak investigations, and collaborating more broadly. The major weakness is that implementation and capacity are uneven across countries and local XB sites. More specifically, these leaders identified the need to more extensively and actively use surveillance information for action (rather than merely 
Table 6 Implementation of specific activities at MBDS XB sites

\begin{tabular}{|c|c|c|c|c|c|c|}
\hline \multirow[t]{2}{*}{ Description (Item) } & \multicolumn{6}{|c|}{ Percentage reporting "Yes" } \\
\hline & ALL & Pairs & Singles & Cambodia & Thailand & Vietnam \\
\hline Number of sites & 15 & 7 & 8 & 6 & 4 & $2^{*}$ \\
\hline \multicolumn{7}{|l|}{ Cross-border (XB) Cooperation } \\
\hline Maintain list of contact info for XB counterparts & $100 \%$ & $100 \%$ & $100 \%$ & $100 \%$ & $100 \%$ & $100 \%$ \\
\hline Have a basic package of activities for your site & $86 \%$ & $86 \%$ & $86 \%$ & $83 \%$ & $75 \%$ & $100 \%$ \\
\hline Shared surveillance information as required & $93 \%$ & $100 \%$ & $86 \%$ & $100 \%$ & $100 \%$ & $100 \%$ \\
\hline Participated in at least one meeting with another XB site in the past 6 months & $57 \%$ & $43 \%$ & $71 \%$ & $83 \%$ & $50 \%$ & $50 \%$ \\
\hline Participated in at least one supervisory visit in the last 6 months & $57 \%$ & $57 \%$ & $57 \%$ & $67 \%$ & $25 \%$ & $100 \%$ \\
\hline Ever participated in joint outbreak investigation & $79 \%$ & $71 \%$ & $86 \%$ & $67 \%$ & $75 \%$ & $100 \%$ \\
\hline Participated in at least one outbreak investigation, TXX or drill past 12 months & $57 \%$ & $43 \%$ & $71 \%$ & $50 \%$ & $50 \%$ & $100 \%$ \\
\hline Average number (of 7 possible) & 5.3 & 5.0 & 5.6 & 5.5 & 4.8 & 6.5 \\
\hline \multicolumn{7}{|l|}{ Animal-human interface and community-based surveillance } \\
\hline Maintain list of priority zoonotic diseases & $86 \%$ & $86 \%$ & $86 \%$ & $83 \%$ & $100 \%$ & $50 \%$ \\
\hline Maintain a list of contact information for local animal \& human health counterparts & $79 \%$ & $86 \%$ & $71 \%$ & $83 \%$ & $75 \%$ & $50 \%$ \\
\hline $\begin{array}{l}\text { Participated in outbreak investigation, TX or drill that at addressed the interface between } \\
\text { animal and human health in the past } 12 \text { months }\end{array}$ & $57 \%$ & $43 \%$ & $71 \%$ & $50 \%$ & $50 \%$ & $100 \%$ \\
\hline Regularly share surveillance reports between animal and human health sectors & $64 \%$ & $57 \%$ & $71 \%$ & $67 \%$ & $25 \%$ & $100 \%$ \\
\hline Have list of suspected diseases or events to report via community-based surveillance & $71 \%$ & $57 \%$ & $86 \%$ & $67 \%$ & $50 \%$ & $100 \%$ \\
\hline Have tested (pilot) or implemented community-based surveillance past 6 months & $36 \%$ & $14 \%$ & $57 \%$ & $50 \%$ & $0 \%$ & $100 \%$ \\
\hline Community-based surveillance fully operational at site & $57 \%$ & $29 \%$ & $86 \%$ & $83 \%$ & $25 \%$ & $50 \%$ \\
\hline Average number (of 7 possible) & 4.5 & 3.7 & 5.3 & 4.8 & 3.3 & 5.5 \\
\hline \multicolumn{7}{|l|}{ Human resource/epidemiology capacity } \\
\hline At least 1 person at site has participated in short- or long-term epidemiology course & $100 \%$ & $100 \%$ & $100 \%$ & $100 \%$ & $100 \%$ & $100 \%$ \\
\hline \multicolumn{7}{|l|}{ ICT capacity } \\
\hline XB site has ICT hardware/software installed, including updates. & $93 \%$ & $100 \%$ & $86 \%$ & $100 \%$ & $100 \%$ & $33 \%$ \\
\hline XB site has received ICT training, including updates as needed. & $79 \%$ & $86 \%$ & $71 \%$ & $100 \%$ & $100 \%$ & $33 \%$ \\
\hline XB site has access to ICT support when needed. & $93 \%$ & $100 \%$ & $86 \%$ & $100 \%$ & $100 \%$ & $33 \%$ \\
\hline XB site routinely uses ICT for surveillance. & $93 \%$ & $100 \%$ & $86 \%$ & $100 \%$ & $100 \%$ & $33 \%$ \\
\hline Average number (of 4 possible) & 3.6 & 3.9 & 3.3 & 4.0 & 4.0 & 2.0 \\
\hline \multicolumn{7}{|l|}{ Laboratory capacity } \\
\hline Site has laboratory for detecting/diagnosing at least 1 priority disease & $71 \%$ & $86 \%$ & $57 \%$ & $83 \%$ & $75 \%$ & $0 \%$ \\
\hline Site has timely access to lab testing for all priority diseases & $36 \%$ & $57 \%$ & $14 \%$ & $33 \%$ & $75 \%$ & $0 \%$ \\
\hline Laboratory at or serving your site participated in proficiency testing past 12 months & $50 \%$ & $43 \%$ & $57 \%$ & $67 \%$ & $50 \%$ & $0 \%$ \\
\hline Average number (of 3 possible) & 1.6 & 1.9 & 1.3 & 1.8 & 2.0 & 0.0 \\
\hline \multicolumn{7}{|l|}{ Risk communications $(R C)$} \\
\hline At least 1 person at your site has received risk communications training & $64 \%$ & $71 \%$ & $57 \%$ & $83 \%$ & $50 \%$ & $0 \%$ \\
\hline Your site has used (in a real situation) or tested (via exercise) RC past 12 months & $43 \%$ & $43 \%$ & $43 \%$ & $67 \%$ & $50 \%$ & $0 \%$ \\
\hline Average number (of 2 possible) & 1.1 & 1.1 & 1.0 & 1.5 & 1.0 & 0.0 \\
\hline Overall average number (of 24 possible) & 17.0 & 16.6 & 17.4 & 18.7 & 16.0 & 15.0 \\
\hline
\end{tabular}

*Only 2 of the 3 sites in Vietnam reported this information.

sharing it) and enhance laboratory capacity across all countries and out to the XB level. Nonetheless, after a decade of experience in working together, they feel that the MBDS cooperation has been successful and the MBDS XB model has contributed importantly to both local disease control and compliance with the IHR. They feel the XB model should be strengthened and expanded-by strengthening local human, laboratory and communications technologies and expanding to more counterpart $\mathrm{XB}$ sites along the expansive MBDS 
borders. One manager noted the political and practical importance of local XB cooperation in areas beyond simply disease surveillance. He further noted that sustainability will depend more on governments integrating MBDS-related activities into their routine programming and providing ongoing financial support to do so, rather than depending on external funding into perpetuity.

\section{Conclusions}

MBDS has more than a decade of experience with its model of local cross-border cooperation in disease surveillance and control. Frontline XB managers strongly support this model and hope it can be sustained and expanded, both within and beyond MBDS. They especially noted the importance of relationships built on trust, which in turn enhance disease surveillance and control at local transborder sites. Senior MBDS officials validated these views, and recent commentaries also support local cross-border cooperation as a promising pathway for the future [16,24]. The MBDS Action Plan spells out seven key strategies, of which six are directly and strongly relevant to all $\mathrm{XB}$ sites and hence were the major focus of our examination, as reported here. Survey respondents indicated that $\mathrm{XB}$ cooperation and epidemiology capacity are the strongest in underpinning current MBDS cooperation; some key capacities remain uneven across the XB sites, especially laboratory and communications technologies/capacities. The challenges to public health surveillance and networking have been described [5,25]. Building and sustaining a full set of critical public health surveillance capacities across all MBDS XB sites will indeed be a challenge for the future. However, the MBDS XB model is standing the test of time as a solid approach to building and sustaining the public health capabilities needed into the future for disease surveillance and control from the local to national and global level.

\section{Additional file}

Additional file 1: Cross-Border Disease Surveillance - Site Manager Questionnaire.

\section{Abbreviations \\ HIV: Human immunodeficiency virus; IHR: International health regulations; MBDS: Mekong basin disease surveillance; SARS: Severe acute respiratory syndrome; TOR: Terms of reference; WHO: World health organization; $\mathrm{XB}$ : Cross-border.}

\section{Competing interests}

The authors declare that they have no competing interests.

\section{Authors' contributions}

MM and DJD designed and conducted the study. MM led the writing and analysis. DJD contributed substantially to the analysis and writing. Both authors have read and approved the final manuscript.

\section{Acknowledgements}

We would like to express our thanks to Dr. Moe Ko Oo (MBDS Coordinator), the MBDS country-level managers with whom we spoke (Dr. Bounlay Phommasak of Lao PDR and Dr. Kumnuan Ungchsak of Thailand), and the 15 MBDS cross-border managers who contributed their perspectives and insights through the survey. We would also like to acknowledge the support of the Rockefeller Foundation (through grant 2008 DSN 302) which generously supported MBDS efforts for more than a decade and also supported this work.

\section{Author details}

${ }^{1}$ Health Unit, RAND Corporation, Arlington, VA, USA. ${ }^{2}$ School of Health

Professions and Public Health, Mercyhurst University, Erie, PA, USA.

Received: 10 January 2014 Accepted: 10 March 2015

Published online: 21 March 2015

\section{References}

1. Institute of Medicine, Davis JR, Lederberg J. Emerging infectious diseases from the global to the local perspective: a summary of a workshop of the forum on emerging infections. Washington, DC: National Academy Press; 2001.

2. Rodier G, Greenspan AL, Hughes JM, Heymann DL. Global public health security. Emerg Infect Dis. 2007;13(10):1447-52.

3. Bond K. Promoting trans-national collaboration in disease surveillance and control. [http://www.rockefellerfoundation.org/newsroom/promotingtrans-national-collaboration]

4. Castillo-Salgado C. Trends and directions of global public health surveillance. Epidemiol Rev. 2010;32:93-109.

5. Moore M, Dausey DJ, Phommasack B, Touch S, Lu G, Lwin Nyein S, et al. Sustainability of sub-regional disease surveillance networks. Global Health Governance. 2012;V(2):1-43. Spring 2012.

6. World Health Organization. International Health Regulations (2005). 2nd ed. Geneva, Switzerland: World Health Organization; 2008.

7. Bond KC, Macfarlane SB, Burke C, Ungchusak K, Wibulpolprasert S. The evolution and expansion of regional disease surveillance networks and their role in mitigating the threat of infectious disease outbreaks. Emerg Health Threats J. 2013;6:19913. http://dx.doi.org/10.3402/ehtj.v6i0.19913.

8. Kimball AM, Moore M, French HM, Arima Y, Kumnuan U, Suwit W, et al. Regional infectious disease surveillance networks and their potential to facilitate the implementation of the International Health Regulations. Med Clin N Am. 2008;92(6):1459-71.

9. Phommasack B, Jiraphongsa C, Oo MK, Bond KC, Phaholyothin N, Suphanchaimat $R$, et al. Mekong Basin Disease Surveillance (MBDS): a trust-based network. Emerging Health Threats J. 2013;6:19944. http://dx. doi.org/10.3402/ehtj.v6i0.19944.

10. Leventhal A, Ramlawi A, Belbiesi A, Sheikh S, Haddadin A, Husseini S, et al. Enhanced surveillance for detection and management of infectious diseases: regional collaboration in the Middle East. Emerging Health Threats J. 2013;6:19955. http://dx.doi.org/10.3402/ehtj.v6i0.19955.

11. Ope M, Sonoiya S, Kariuki J, Mboera LEG, Gandham RNV, Schneidman M, et al. Regional initiatives in support of surveillance in East Africa: The East Africa Integrated Disease Surveillance Network (EAIDSNet) experience. Emerging Health Threats J. 2013;6:19948. http://dx.doi.org/10.3402/ehtj. v6i0.19948.

12. Rweyemamu MM, Mmbuji P, Karimuribo E, Paweska J, Kambarage D, Neves $L$, et al. The Southern African Centre for Infectious Disease Surveillance: A One Health consortium. Emerg Health Threats J. 2013;6:19958. http://dx.doi. org/10.3402/ehtj.v6i0.19958.

13. Bino $S$, Cavaljuga $S$, Kunchev A, Lausevic D, Kaic B, Pistol A, et al. Southeastern European Heatlh Network (SEEHN) communicable diseases surveillance: A decade of bridging trust and collaboration. Emerg Health Threats J. 2013;6:19950. http://dx.doi.org/10.3402/ehtj.v6i0.19950.

14. Weinberg M, Waterman S, Alvarez Lucas C, Carrion Falcon V, Kuri Morales P, Anaya Lopez L, et al. The U.S.-Mexico Border Infectious Disease Surveillance Project: Establishing bi-national border surveillance. Emerg Infect Dis. 2003:9(1):97-102.

15. Moore M, Dausey DJ. Response to the 2009-H1N1 influenza pandemic in the Mekong Basin: surveys of country health leaders. BMC Res Notes. 2011:4:361.

16. MacPherson N, Kimball AM, Burke C, Abernethy N, Tempongko S, Zinsstag J. Key findings and lessons learned from an evaluation of the Rockefeller 
Foundation Disease Surveillance Networks Initiative. Emerging Health Threats J. 2013;6:19959.

17. Gresham L, Smolinski M, Suphanchaimat R, Kimball AM, Wibulpolprasert S. Creating a global dialogue on infectious disease surveillance: Connecting Organizations for Regional Disease Surveillance (CORDS). Emerging Health Threats J. 2013;6:19912.

18. Mekong Basin Disease Surveillance Cooperation Action Plan: 2011_2016. 2011. [http://mbdsoffice.com/data140508/mbds_master_plan_2011_16_ final_eb_approved_2010_11.pdf]

19. Baker MG, Fidler DP. Global public health surveillance under new International Health Regulations. Emerg Infect Dis. 2006;12(7):1058-65.

20. Jebara KB. Surveillance, detection and response: managing emerging diseases at national and international levels. Rev Sci Tech Off Int Epiz. 2004;23(2):709-15

21. Käferstein FK, Motarjemi Y, Bettcher DW. Foodborne disease control: a transnational challenge. Emerg Infect Dis. 1997;3(4):503-10.

22. Skinner $\mathrm{H}$, Abdeen $\mathrm{Z}$, Abdeen $\mathrm{H}$, Aber P, Al-Masri M, Attias J, et al. Promoting Arab and Israeli cooperation: peacebuilding through health initiatives. Lancet. 2005;365:1274-7.

23. Coker RJ, Hunter BM, Rudge JW, Liverani M, Hanvoravongchai P. Emerging infectious diseases in Southeast Asia: regional challenges to control. Emerg Infect Dis. 2011;377:599-609.

24. Moore M, Bond KC, Gresham L, Rweyemamu M, Chowdhury MR, Bino S. Promising pathways for regional disease surveillance networks. Emerging Health Threats J. 2013;6:19961.

25. Cash R, Narasimhan V. Impediments to global surveillance of infectious diseases: consequences of open reporting in a global economy. Bull World Health Organ. 2000;78(11):1358-67.

\section{Submit your next manuscript to BioMed Central and take full advantage of:}

- Convenient online submission

- Thorough peer review

- No space constraints or color figure charges

- Immediate publication on acceptance

- Inclusion in PubMed, CAS, Scopus and Google Scholar

- Research which is freely available for redistribution 